\title{
EL SEGURO DE CAUCIÓN O DE GARANTÍA
}

\author{
SURETY BOND INSURANCE
}

\author{
JOEL GONZÁLEZ CASTILLO* \\ Prof. de Derecho Civil \\ Pontificia Universidad Católica de Chile \\ Santiago - Chile
}

\section{RESUMEN}

El objeto de este artículo es analizar el seguro de caución, también llamado seguro de garantía o de cumplimiento, el cual no obstante su intenso uso en el tráfico mercantil sólo tuvo una regulación legal en 2013 con la dictación de la Ley $N^{\circ} 20.667$ que modificó el Código de Comercio. El trabajo se estructura como sigue: lo primero que se hace es distinguir este seguro de aquel otro llamado seguro de crédito con el cual presenta algunas semejanzas, luego se aborda su naturaleza jurídica distinguiéndolo de la fianza; las partes que intervienen, destacando que se trata de un seguro por cuenta ajena; las obligaciones que pueden garantizarse con este tipo de seguros 0 en otras palabras la cobertura del mismo; sus efectos, precisándose los relativos al asegurado o beneficiario, tomador y asegurador, este último, como se explica, obligado al pago del seguro aunque la prima no se haya pagado; se concluye con un análisis de los seguros de garantía "a primer requerimiento" reconocidos ahora en nuestro ordenamiento por la legislación citada, y la vigencia del seguro.

Palabras clave: Seguros, caución, incumplimiento, primer requerimiento.

* Profesor de Derecho Civil, Pontificia Universidad Católica de Chile. Correo: jagonzac@uc.cl. Artículo recibido para su revisión el 21 de marzo de 2018, y aprobado para su publicación el 25 de mayo de 2018. 


\begin{abstract}
The purpose of this article is to analyze surety insurance, also called guarantee or fulfillment insurance, which despite its intense use in commercial traffic only had a legal regulation in 2013 with the enactment of Law $\mathrm{N}^{\circ}$ 20.667, which modified the Código de Comercio. The work is structured as follows: the first thing that is done is to distinguish this insurance from another one called credit insurance with which it has some similarities, then its legal nature is approached, distinguishing it from the bail bond; the parties involved, highlighting that it is insurance for someone else; the obligations that can be guaranteed with this type of insurance or in other words the coverage of it; its effects, specifying those relating to the insured or beneficiary, policyholder and insurer, the latter, as explained, is obliged to pay the insurance even if the premium has not been paid; it concludes with an analysis of the "on first demand" surety insurance, now recognized in our legislation by the aforementioned legislation and the period of validity of the insurance.
\end{abstract}

Keywords: Insurance, surety, breach of contract, on first demand.

\title{
I. DEFINICIÓN
}

Una primera cuestión que hay que aclarar para un análisis correcto de lo que sigue son los conceptos de seguro de crédito y seguro de caución porque no siempre es fácil su distinción según veremos.

El artículo 11 inciso $3^{\circ}$ del D.F.L. $N^{\circ} 251$ sobre Compañías de Seguros señala: "Los riesgos de crédito deberán ser asegurados sólo por compañías del primer grupo que tengan por objeto exclusivo precisamente cubrir este tipo de riesgo, pudiendo, además, cubrir los de garantía y fidelidad". A continuación, en su inciso $4^{\circ}$ define los seguros de crédito como aquellos "que cubren los riesgos de pérdidas o deterioro en el patrimonio del asegurado, producto del no pago de una obligación en dinero o de crédito de dinero". ${ }^{1}$

\footnotetext{
${ }^{1}$ La Ley N ${ }^{\circ} 20.667$ de 9 de mayo de 2013 reguló en el Código de Comercio el seguro de crédito en los siguientes términos: “Art. 579. Concepto. Por el seguro de crédito el asegurador se obliga a indemnizar al asegurado las pérdidas que experimente por el incumplimiento de una obligación de dinero. Art. 580. Procedencia del reclamo de indemnización. Habrá lugar al pago del seguro: a) Cuando el deudor haya sido declarado en quiebra mediante resolución judicial firme. b) Cuando
} 
El seguro de garantía, objeto de este artículo, también conocido como seguro de caución, seguro de cumplimiento o seguro de fianza ${ }^{2}$ fue regulado por la Ley $\mathrm{N}^{\circ} 20.667$ de 9 de mayo de 2013 que modificó el Código de Comercio disponiendo ahora su artículo 582: “Concepto. Por el seguro de caución el asegurador se obliga a indemnizar al asegurado los daños patrimoniales sufridos en caso de incumplimiento por el tomador del seguro o afianzado, de sus obligaciones legales o contractuales...”.

El concepto dado por nuestro legislador está claramente inspirado en la legislación española donde el artículo 68 de la Ley $N^{\circ}$ 50/1980 sobre el Contrato de Seguro dispone: "Por el seguro de caución el asegurador se obliga, en caso de incumplimiento por el tomador del seguro de sus obligaciones legales o contractuales, a indemnizar al asegurado a título de resarcimiento o penalidad los daños patrimoniales sufridos, dentro de los límites establecidos en la ley o en el contrato. Todo pago hecho por el asegurador deberá serle reembolsado por el tomador del seguro".

En el plano doctrinal, de acuerdo a Broseta Pont seguros de caución "son los que suelen estipularse para garantizar que serán resarcidos al acreedor de una obligación no directamente dineraria, los daños que puede provocar su incumplimiento". ${ }^{3}$ En Chile se ha definido el seguro de garantía como un "contrato en virtud del cual una parte, asegurador, se obliga para con otra, asegurado, a indemnizarle los daños patrimoniales que un tercero afianzado, le cause con ocasión del incumplimiento de una o más obligaciones contractuales de hacer o no hacer". ${ }^{4}$

No siempre es fácil determinar si se está en presencia de un seguro de crédito o de garantía. Así, se discutió en un juicio arbitral si la póliza que garantizaba el pago de las diferencias que pudieran producirse por los

\footnotetext{
haya celebrado con sus acreedores, convenios regulados por la Ley de Quiebras que le otorguen condonaciones. c) Cuando habiendo sido demandado ejecutivamente, se establezca que el deudor no posee bienes suficientes para solucionar la deuda o que, por su ocultamiento, se haga imposible la prosecución del juicio. d) Si el asegurado y el asegurador acuerdan que el crédito resulta incobrable. e) En los demás casos que acuerden las partes. Art. 581. Gastos de cobranza. Las partes podrán convenir que, además del monto de la deuda impaga, la suma asegurada cubra también los gastos originados por las gestiones de cobranza y cualesquiera otros”.

${ }^{2}$ La literatura específica sobre este tipo de seguros no es abundante pudiendo citarse: BARRES Benlloch, María Pilar, Régimen Jurídico del Seguro de Caución, Aranzadi, Pamplona, 1996; CAMACHo De los Ríos, Javier, El Seguro de Caución. Estudio Crítico, Mapfre, Madrid, 1994; BACHILler NúÑEz, Julio; BACHILler, Sergio; PÉREz EtChegoyen, Julia, Seguro de Caución, Abeledo Perrot, Buenos Aires, 1995; Hoyos Elizalde, Carlos, El Seguro de Caución: una aproximación práctica, Mapfre, Madrid, 2007.

${ }^{3}$ Broseta Pont, Manuel, Manual de Derecho Mercantil, Tecnos, Madrid, 1991, p. 573.

${ }^{4}$ Faraggi, Salazar, Contreras y GoÑ Abogados (EDITOR), "El Seguro de Garantía”, en AA.VV., Re-Capacitando, Compañía Reaseguradora Bernardo O’Higgins S.A., Santiago, 1985, Vol. I., p. 83.
} 
cambios que experimentara el valor patrimonial de la empresa, objeto de negociación entre las partes, era seguro de crédito o de garantía. El árbitro señaló que la obligación directamente caucionada por la póliza era la obligación pecuniaria sustitutiva de pagar una indemnización en caso que el valor aludido no correspondiere a la realidad, la que no es una que pueda satisfacerse directamente en dinero, sino sólo sustitutivamente por vía de indemnización y que, por lo tanto, se trataba de un seguro de garantía, pues: "Seguro de crédito es aquel que cubre los riesgos de pérdidas o deterioro en el patrimonio del asegurado, producto del no pago de una obligación en dinero o de crédito de dinero. Seguro de garantía es aquel que cubre las pérdidas en dinero que le irrogue al asegurado el incumplimiento por parte del tercero de las obligaciones provenientes del contrato o convención individualizados en las Condiciones Particulares que no deban satisfacerse directamente en dinero". ${ }^{5}$

\section{NATURALEZA JURÍDICA}

Se ha sostenido que el seguro de garantía sería un verdadero contrato de fianza prestado por una entidad de seguros y participaría de su naturaleza jurídica. En el seguro de caución prevalecería su naturaleza intrínseca de fianza, frente a la condición externa, meramente formal, de seguro otorgada por el legislador al incluir a la figura entre las modalidades que pueden ofrecer las compañías de seguros. Pero como aclara Achurra, si bien existe cierta semejanza entre el seguro de garantía y la fianza, porque ambos son cauciones personales, la verdad es que se trata de dos contratos diferentes y que, al menos de acuerdo a la ley chilena, el seguro de garantía tiene la naturaleza jurídica de un contrato de seguro, que reúne todas sus características y elementos esenciales. Las razones que permiten llegar a esta conclusión son las siguientes:

a. El texto expreso de diversas disposiciones legales (artículo 11 de la Ley sobre Compañía de Seguros, artículo 109 de la Ley Orgánica del Ministerio de Obras Públicas y artículo 129 del D.F.L. $N^{\circ} 458$ que contiene la Ley General de Urbanismo y Construcciones) aluden claramente a la póliza, seguro o riesgo de garantía, en razón de lo cual, y frente a esa clara determinación legal, no corresponde dar o atribuir al contrato una naturaleza jurídica diferente a la del seguro.

\footnotetext{
${ }^{5}$ Vid. Contreras Strauch, Osvaldo, Jurisprudencia sobre Seguros. Recopilación y Análisis, Editorial Jurídica de Chile, Santiago, 1999, T. III, pp. 1161-1165.
} 
b. Conforme al artículo $4^{\circ}$ del D.F.L. $N^{\circ}$ 251, el comercio de asegurar riesgos a base de primas sólo puede hacerse en Chile por sociedades anónimas nacionales de seguro que tengan por objeto exclusivo el desarrollo de dicho giro y actividades que sean afines o complementarias a éste. Si se estimara que las pólizas de garantía no constituyen un contrato de seguro sino de fianza, las compañías estarían impedidas de celebrarlas porque excederían del giro y objeto exclusivo que la ley les reserva.

c. El contrato de seguro de garantía, tal como todo contrato de seguro, es un contrato solemne que se perfecciona mediante la emisión de la póliza de acuerdo a lo que exige el artículo 514 del Código de Comercio. En cambio, el contrato de fianza es consensual, lo que significa que nace a la vida jurídica por el solo consentimiento de las partes.

d. El seguro de garantía es un contrato dirigido, lo que se traduce en que el texto o condiciones generales del contrato debe ser previamente aprobado o registrado en la Superintendencia de Seguros, como lo exige el artículo $3^{\circ}$ del D.F.L. $\mathrm{N}^{\circ}$ 251. En cambio, los términos y condiciones del contrato de fianza se pactan entre las partes con absoluta libertad.

e. Es de la naturaleza del contrato de fianza el llamado "beneficio de excusión”, según el cual el fiador tiene derecho a exigir del acreedor que se dirija primera y previamente contra el deudor y sólo una vez que esto no ha dado resultado, en contra del fiador. En el seguro de garantía, es normal que no exista el beneficio de excusión, lo que significa que la compañía se encuentre en la necesidad de pagar la correspondiente indemnización, sin que el acreedor o asegurado haya debido dirigirse primero contra el deudor principal.

f. El contrato de fianza no es remunerado, lo que significa que el fiador no tiene derecho a cobrar una retribución por desempeñar la calidad de tal, a menos que se haya estipulado expresamente lo contrario, en cuyo caso la fianza se denomina fianza remunerada. En cambio, el contrato de seguro de garantía es siempre remunerado, por cuanto la prima es un elemento esencial de todo contrato de seguro, de tal manera que de no haber estipulación de prima el contrato sería nulo o inexistente, cosa que no ocurre con el contrato de fianza. ${ }^{6}$

g. Otra distinción de importancia es la referente al número de partes que resultan obligadas en el contrato. La fianza es por naturaleza un contrato unilateral, es decir, de él resulta obligada una sola parte, de manera tal, que será sólo el fiador quien se obligue a pagar una deuda en el

${ }^{6}$ Cfr. Achurra Larraín, Juan, “Aspectos Jurídicos del Seguro de Garantía”, en AA.VV., ReCapacitando, American Re-Insurance Company (Chile) S.A., Santiago, 1992, Vol. II, pp. 259260. 
evento que no lo haga el deudor principal, y el acreedor por su parte no asumirá obligación alguna. El seguro de garantía, en cambio, es un contrato bilateral en virtud del cual asegurador y afianzado -comúnmente llamado tercero en las pólizas- contraen obligaciones recíprocas, siendo las más importantes las de pagar la prima, por una parte, y concurrir al pago de los perjuicios en el evento de siniestro, por la otra. ${ }^{7}$

h. La fianza puede garantizar cualquier clase de obligación (arts. 2338 y 2343 del Código Civil). El seguro de caución sólo puede referirse a obligaciones de hacer o no hacer, según explicaremos en el apartado referente a la cobertura del seguro de garantía.

i. Mientras la fianza es un contrato por el cual el fiador se obliga a cumplir por el deudor principal en caso de incumplimiento de éste, en el seguro de caución el asegurador se obliga, no a cumplir por el deudor principal, sino a resarcir al acreedor de los daños y perjuicios que aquel incumplimiento le hubiera producido, de donde se desprende que para que el fiador resulte obligado a satisfacer la obligación por él contraída es suficiente el incumplimiento del afianzado cuya posición asume, mientras que la obligación de resarcimiento asumida por el asegurador requiere, además de ese incumplimiento, que como consecuencia del mismo se hayan causado daños y perjuicios al asegurado.

Todo lo anterior ha llevado, justificadamente, a Molina a criticar que los nuevos artículos 582 y 583 del Código de Comercio que tratan del seguro de garantía hablen del "afianzado".

\section{PARTES QUE INTERVIENEN}

En el seguro de garantía intervienen tres partes:

El asegurador, es decir, la compañía de seguros que garantiza al acreedor o beneficiario el cumplimiento de la obligación contraída por el afianzado.

El tomador o afianzado, que es el deudor que contrata el seguro y cuyas obligaciones son garantizadas mediante la póliza de seguro. Cabe señalar que en el seguro de garantía se aplica la figura jurídica del seguro contratado por cuenta ajena ${ }^{9}$ a que se refiere el artículo 516 del Código de

\footnotetext{
${ }^{7}$ FAraggi, Salazar, Contreras y GoÑI. Abogados (editores), cit. (n. 4), pp. 81-82.

${ }^{8}$ Molina Zaldívar, Carlos, “Artículo 583”, en AA.VV., El Contrato de Seguro. Comentarios al Título VIII, Libro II del Código de Comercio, Thomson Reuters, Santiago, 2015, pp. 714-715.

9 "Por otra parte, la doctrina dominante ha venido considerando el seguro por cuenta ajena como un negocio a favor de tercero, basándose para ello en dos aspectos fundamentales; por un lado, en el hecho de que las obligaciones que emergen del seguro por cuenta ajena recaen sobre el
} 
Comercio: "Modos de contratar el seguro. Seguro por cuenta ajena. El seguro puede ser contratado por cuenta propia, o por la de un tercero en virtud de un poder especial o general, y aun sin su conocimiento y autorización. También podrá contratarse por cuenta de un tercero indeterminado pero determinable, según lo estipulen las partes, individualizando al asegurado en la póliza bajo la fórmula 'a quien corresponda'. Se entiende que el seguro corresponde al que lo ha contratado, toda vez que la póliza no exprese que es por cuenta o a favor de un tercero. En los seguros por cuenta ajena, si el tomador se encuentra en posesión de la póliza, tiene el derecho a cobrar la indemnización, pero el asegurador tiene derecho a exigir que el tomador acredite previamente el consentimiento del asegurado o demuestre que obra por mandato de éste o en razón de una obligación o interés legal”.

La tercera parte del seguro de garantía es el asegurado o beneficiario, que es el acreedor o persona a cuyo favor se emite la póliza y que tiene derecho a cobrar la respectiva indemnización en caso de siniestro, o sea, en caso de incumplimiento de la obligación del deudor garantizada por el contrato de seguro.

\section{COBERTURA DEL SEGURO DE GARANTÍA}

Cualquier obligación de hacer o no hacer, legal ${ }^{10}$ o contractual, puede ser amparada por un seguro de garantía con la excepción de las

patrimonio del tomador y no sobre el del asegurado y, por otro lado, en que los derechos resultantes del contrato -en especial el derecho al pago de la prestación- corresponden al asegurado”. CAMACHO DE LOS Ríos, cit. (n. 2), p. 75.

10 Diversos cuerpos legales exigen la contratación de una garantía, entre ellas los seguros de garantía, para responder del cumplimiento de las obligaciones que impone la ley. Así, la Ley $\mathrm{N}^{\circ}$ 19.932 que modifica la Ley General de Urbanismo y Construcciones, en materia de contrato de promesa de compraventa de determinados bienes raíces en su artículo $1^{\circ}$ agregó el siguiente artículo 138 bis a la referida ley: "Las personas naturales o jurídicas que tengan por giro la actividad inmobiliaria o aquellas que construyan o encarguen construir bienes raíces destinados a viviendas, locales comerciales u oficinas, y que celebren contratos de promesa de compraventa, deberán otorgarlos mediante instrumentos privados autorizados ante notario y caucionarlos mediante póliza de seguro o boleta bancaria, aceptada por el promitente comprador”; la Ley $\mathrm{N}^{\circ}$ 20.720 sobre reorganización y liquidación de empresas y personas en su artículo 16 dispone: “Garantía de fiel desempeño. Todo Veedor mantendrá en la Superintendencia y mientras subsista su responsabilidad, una garantía (...). La garantía podrá consistir en una boleta bancaria de garantía, póliza de seguro o cualquiera otra que la Superintendencia determine mediante norma de carácter general (...). La garantía a que se refiere este artículo tiene por objetivo caucionar el fiel desempeño de la actividad del Veedor y asegurar el correcto y cabal cumplimiento de todas sus obligaciones, incluyendo la eventual indemnización a que sea condenado en caso de hacerse efectiva su responsabilidad civil y el pago de las multas administrativas impuestas en su contra" (lo dicho se aplica a los liquidadores por la remisión que hace el art. 32 № 5); la Ley $\mathrm{N}^{\circ} 18.045$ 
obligaciones de dinero o de crédito de dinero (obligaciones de dar) que son objeto del seguro de crédito según el artículo 11 inciso $4^{\circ}$ de la Ley sobre Compañías de Seguros y artículo 579 del Código de Comercio.

El contenido del seguro consiste en garantizar el fiel y oportuno cumplimiento de la obligación contraída por el deudor o tomador del seguro. Se comprende el incumplimiento total y el cumplimiento parcial, defectuoso o tardío, el incumplimiento culpable y ¿también el incumplimiento doloso?

Hasta la dictación de la Ley $N^{\circ} 20.667$ de 9 de mayo de 2013 el artículo 552 del Código de Comercio disponía: "El asegurador no está obligado a indemnizar la pérdida o deterioro procedentes de vicio propio de la cosa, de un hecho personal del asegurado o de un hecho ajeno que afecte civilmente la responsabilidad de éste. Sin embargo, el asegurador puede tomar sobre sí, en virtud de una estipulación expresa, los riesgos provenientes de vicio propio de la cosa; pero le es prohibido constituirse responsable de los hechos personales del asegurado". ${ }^{11}$ En el juicio de rescisión de contrato interpuesto por el Consorcio General de Seguros S.A. contra la empresa constructora Inversiones Bilbao S.A. y SERVIU, en que la compañía aseguradora negó el pago de la póliza aduciendo, entre otros motivos, la omisión (dolosa) de informaciones que la constructora y SERVIU habrían debido otorgarle, y que por lo mismo los seguros de garantía serían nulos pues los hechos dolosos y personales no podrían ser objeto de seguro conforme al artículo 552 del Código de Comercio, el juez de la causa sentenció: "Por definición, el seguro (de garantía) cubre el incumplimiento de obligaciones, sea que dicho incumplimiento provenga de culpa, dolo u otro hecho imputable al deudor afianzado y es precisamente el incumplimiento doloso o fraudulento de la obligación garantizada el caso más evidente de incumplimiento, el que por ende autoriza al acreedor beneficiario a hacer efectiva la póliza. Por lo demás, no puede olvidarse que en el caso de que se trata, el seguro contratado es de carácter especial; en efecto, se trata del seguro de garantía y, por su esencia, éstos cubren precisamente hechos personales del contratante del seguro. En

sobre mercado de valores señala: "Los corredores de bolsa y los agentes de valores deberán constituir una garantía previa al desempeño de sus cargos, para asegurar el correcto y cabal cumplimiento de todas sus obligaciones como intermediarios de valores, en beneficio de los acreedores presentes o futuros que tengan o llegaren a tener en razón de sus operaciones de corretaje (...). La garantía podrá constituirse en dinero efectivo, boleta bancaria, póliza de seguros o prenda sobre acciones de sociedades anónimas abiertas u otros valores de oferta pública y se mantendrá reajustada en la misma proporción en que varíe el monto de las unidades de fomento”.

11 El actual artículo 535 del Código de Comercio dice: "Casos de dolo y culpa grave. El asegurador no está obligado a indemnizar el siniestro que se origine por dolo o culpa grave del asegurado o del tomador en su caso, salvo pacto en contrario para los casos de culpa grave”. 
todo caso, no está de más decir que, en la especie, las pólizas de seguro no cubren ningún hecho personal del SERVIU que, como se ha expresado, no es parte en los respectivos contratos”. 12

El deudor -y consiguientemente la compañía de seguros- no responde, sin embargo, del incumplimiento de la obligación proveniente de un caso fortuito o fuerza mayor, a menos que exista una estipulación en contrario en el contrato o una norma expresa de la ley (art. 1547 del Código Civil).

\section{CONTRATACIÓN DEL SEGURO DE GARANTÍA}

Al igual que la gran mayoría de los seguros, la emisión de la póliza de garantía comienza con la solicitud de seguro que, generalmente en un formulario predispuesto por la propia compañía, debe llenar el tomador.

En dicha solicitud deben identificarse claramente la persona del tomador o afianzado, el contrato y/o las obligaciones que se persigue garantizar y la persona del asegurado, beneficiario del seguro.

Junto a la solicitud deben acompañarse los documentos relativos a la negociación que vincula al tomador con el beneficiario, de donde arrancan las obligaciones del primero que se pretende garantizar y otros antecedentes legales relacionados con la persona del tomador, en especial, si se trata de una persona jurídica, los que conciernen a la personería de quien comparece a su nombre.

Por último, el tomador debe acreditar ante la compañía su solvencia o capacidad económica, por medio de balances y estados de resultados, inventario de bienes que posea, etc., que en este tipo de seguro son de gran importancia, puesto que la solvencia del afianzado puede incidir en su cumplimiento o incumplimiento; en otros términos, el grado del riesgo que asumirá el asegurador. Del mismo modo, la mayor o menor solvencia del tomador del seguro tendrá influencia en el posterior derecho a recupero que en favor del asegurador que paga, reconoce la legislación y la póliza.

Una vez que el asegurador ha evaluado el riesgo con los antecedentes indicados, antes de entregarle la póliza al tomador, el asegurador le exige una contragarantía, esto es, un medio por el cual aquél le asegure el reintegro de lo que éste tenga que pagar al asegurado por concepto de indemnización. Las contragarantías van desde un simple pagaré que el tomador suscribe en favor de la compañía, con algunas de sus menciones

\footnotetext{
12 Segundo Juzgado Civil de Concepción, 31 de julio de 1999, Rol N ${ }^{\circ}$ 80.602-99, cons. $28^{\circ}$. Confirmada por la Corte de Apelaciones de Concepción, 19 de julio de 2000, Rol N 858-97.
} 
en blanco e instrucciones para llenarlas con los datos concernientes al monto y fecha, hasta fianzas de terceros y, en casos muy especiales, algunos tipos de garantías reales.

Evaluado el riesgo, aceptada la solicitud de celebrar el contrato de seguro y entregadas por el tomador las contragarantías, el asegurador procede a emitir y hacer entrega de la póliza, que es el instrumento -en nuestro país el único- que perfecciona y acredita el contrato. Las pólizas constan de dos partes: a) Las condiciones particulares, que son aquellas en las que se identifica al tomador o afianzado, el contrato u obligaciones garantizadas, la persona del beneficiario, la vigencia del seguro y el monto de la prima o precio del seguro, y b) Las condiciones generales, que son aquellas en las que se describen los alcances jurídicos de la cobertura, el riesgo, los derechos y obligaciones de las partes, los procedimientos en caso de siniestro y la forma en que se determina y paga la indemnización. Son estas últimas, las condiciones generales, aquellas que constan en formularios preimpresos según modelos registrados ante la Superintendencia de Valores y Seguros, siendo prohibida la contratación bajo cláusulas no registradas, a menos que se trate de contratos celebrados con asegurados y beneficiarios que sean personas jurídicas y en los que el monto de la prima anual no sea inferior a 200 U.F., debiendo el tomador y el asegurador firmar la póliza (D.F.L. 251 sobre compañías de seguros, art. $3^{\circ}$ letra e).

\section{EFECTOS DEL SEGURO DE GARANTÍA}

\subsection{Obligaciones del tomador}

6.1.1. Pagar la prima en la forma y época convenidas.

En la generalidad de los modelos de pólizas de seguros de garantía actualmente vigentes en Chile, la falta de pago de la prima no es causal de resolución del contrato, no faculta al asegurador para poner término anticipado al seguro y ni siquiera le permite invocar la excepción de contrato no cumplido. En suma, el asegurador debe pagar la indemnización frente al asegurado, aunque la prima esté impaga, lo que se comprende, toda vez que el beneficiario, quien frente a la negociación del contrato de seguro es -en la inmensa mayoría de los casos- un tercero absoluto, no puede sufrir las consecuencias jurídicas de la falta de pago de la prima, porque en ese caso el instrumento perdería gran parte de su eficacia. Esto se desarrollará más en extenso en el apartado sobre pago de la prima. 
Como explica Molina la falta de pago de la prima por regla general producirá el término del contrato. Sin embargo, en el seguro de caución el no pago de la prima por parte del tomador o contratante no faculta al asegurador a poner término al contrato ni tampoco lo exime de su obligación de indemnizar. El obligado al pago de la prima en un seguro de este tipo es el tomador sin que en consecuencia resulte exigible el pago de la misma al asegurado o beneficiario de la caución. Desde este punto de vista, resultaría del todo injustificado que el obligado al pago de la garantía, que no es otra que la compañía de seguros que ha emitido la póliza, pueda poner término al seguro o peor aún, al momento de requerirse su cobro, excusarse del pago alegando que el tomador o contratante del seguro no ha cumplido con la obligación de pagar la prima. Lo anterior restaría toda eficacia y certeza jurídica al seguro de caución, por cuanto el asegurado se vería perjudicado al no recibir el pago de la garantía, por un hecho originado en el incumplimiento ya no de la obligación caucionada por la póliza, sino por el incumplimiento del tomador de su obligación de pagar la prima o precio del contrato. Si bien lo anterior, dice el mismo autor, no fue reconocido expresamente en los artículos 582 y 583, el no pago de la prima no faculta al asegurador para dar por terminado el contrato tal como lo dispone el artículo 528. La citada disposición no resulta aplicable al seguro de caución por diversas razones. En efecto, se trata de un seguro tripartito, en donde la obligación de pagar la prima compete al tomador o contratante de la póliza. Por otra parte, la póliza de caución constituye una garantía que el tomador extiende a favor del asegurado, el cual no se encuentra obligado al pago de la prima. Por último, y a la luz de lo dispuesto en el inciso final del artículo 583, el asegurador se encuentra obligado a respetar la naturaleza de la póliza de caución, sin que la oposición de excepciones pueda ser invocada para condicionar o diferir el pago de la indemnización. La compañía de seguros, en consecuencia, no puede excepcionarse de su obligación de indemnizar, alegando la falta de pago de la prima, por cuanto se trata de una obligación que sólo resulta exigible al tomador o contratante. Como contrapartida, el asegurador tiene derecho a exigir el pago de la prima al tomador, para lo cual podrá compelerlo judicialmente, e incluso ejecutando las contragarantías que el tomador ha otorgado en su favor al momento de solicitar la emisión de la caución. ${ }^{13}$

\footnotetext{
${ }^{13}$ MolinA, cit. (n. 8), pp. 728-729.
} 
6.1.2. Restituir al asegurador toda suma que éste haya debido pagar al asegurado en caso de hacerse efectiva la póliza.

Una vez pagada la indemnización por el siniestro, nace para la compañía aseguradora el derecho de recuperar la totalidad de lo pagado del tomador o afianzado cuya obligación incumplida dio origen al siniestro.

La obligación de reembolsar la suma pagada por concepto de siniestro se aplica a todos los seguros de garantía. En los demás contratos de seguros, la obligación de reembolsar no afecta al tomador del seguro, sino al que sea responsable de la ocurrencia de un determinado siniestro. Lo que ocurre es que en el seguro de caución el tomador es el desencadenante del siniestro en el sentido de que si toma el seguro es para resarcir las consecuencias que tenga su incumplimiento de obligaciones contractuales o legales.

Esta obligación está establecida así en el contrato de seguro y, por consiguiente, bastaría ese solo título para que el afianzado se vea en la necesidad de reembolsar lo que la compañía aseguradora pagó por su cuenta. Pero además de la estipulación del contrato de seguro de garantía, la obligación de reembolsar que afecta al tomador del seguro en favor de la compañía aseguradora está establecida expresamente ahora por la ley: "Todo pago hecho por el asegurador deberá serle reembolsado por el tomador del seguro" (art. 582, inc. $1^{\circ}$ in fine del Código de Comercio).

Por otra parte "las excepciones o defensas que el tomador oponga al asegurado, alegando que no ha existido incumplimiento de las obligaciones garantizadas por la póliza, no obstarán a que el asegurador pague la indemnización solicitada" (art. 582, inc. $2^{\circ}$ del mismo Código). Dichas defensas o alegaciones deben discutirse directamente entre el tomador afianzado y el asegurado beneficiario, y no pueden perjudicar los derechos de la compañía aseguradora para que se le restituya toda suma que haya pagado por concepto de siniestro.

Antes de la incorporación del citado artículo 582 por la ley $\mathrm{N}^{\circ} 20.667$ de 9 de mayo de 2013, Contreras y Prado observaban que "la característica de que las pólizas de 'ejecución inmediata', 'a solo requerimiento' o 'de pronto pago' que han surgido en el último tiempo, no conceden al asegurador mayores posibilidades de objetar el cobro que exige el asegurado, ni requieren como condición previa al curso de la indemnización, la opinión del afianzado, supuesto incumplidor de las obligaciones garantizadas, puede dar lugar a que al intentarse el recobro, el afianzado alegue la inexistencia del siniestro, la circunstancia de que no es efectivo su incumplimiento de las obligaciones garantidas y que, no logrando rendir el asegurador prueba en contrario, se vea privado de 
obtener el recupero por una situación que, teóricamente al menos, habría optado al pago de la indemnización. Pensamos que, en este caso, cabe el derecho de perseguir el reintegro de la suma pagada al acreedor, porque estaríamos evidentemente en presencia de un enriquecimiento ilícito. Ahora bien: ¿Quién lo ejerce? ¿El afianzado, quien no podría oponer al asegurador una excepción de pago indebido, o, por el contrario, admitida dicha excepción, el asegurador por no haber podido obtener de dicho afianzado el recobro? La doctrina extranjera (Garrigues, Tirado Suárez, Olivencia, Gómez Calero) está dividida en cuanto a si el tomador puede oponer al asegurador la excepción de pago indebido del seguro, fundada en que no es efectivo el incumplimiento que se le imputó y que constituyó el fundamento último del cobro del seguro, siendo mayoritaria la tesis de los que sustentan que es admisible la excepción de pago indebido por el tomador a la compañía aseguradora”. ${ }^{14}$

\subsection{Obligaciones del asegurado o beneficiario}

\subsubsection{Comunicar al asegurador la ocurrencia del siniestro.}

Esta obligación debe cumplirse en la forma estipulada en la póliza, y a falta de tal estipulación, de la manera en que tal obligación está establecida en el artículo $524 \mathrm{~N}^{\circ} 7$ del Código de Comercio, que es aplicable a toda clase de contratos de seguros: "Notificar al asegurador, tan pronto sea posible una vez tomado conocimiento, de la ocurrencia de cualquier hecho que pueda constituir o constituya un siniestro". ${ }^{15}$

14 Contreras Strauch, Osvaldo; Prado Puga, Arturo. El Contrato de construcción y sus Principales Garantías, Colegio de Abogados de Chile, Santiago, 1996, pp. 33-34.

${ }^{15}$ Sobre esto se ha resuelto: "PRIMERO: Que tal como se advierte del claro tenor de los escritos formalizados por las partes durante la etapa de discusión, la controversia sub lite se halla circunscrita, en este caso, a resolver (...) la fecha máxima en que debieron las aseguradas efectuar el denuncio del siniestro; SEGUNDO: Que, ahora bien, para una adecuada inteligencia del asunto y resolución del recurso de apelación interpuesto, cabe tener presente que tras la valoración legal de la prueba rendida en el proceso resultan ser circunstancias fácticas establecidas en él, las siguientes: a) En distintas fechas entre el 1 de septiembre de 2006 y el 6 de febrero de 2007 las demandantes celebraron indistintamente con Inmobiliaria Benanto S.A. nueve promesas de compraventa de inmuebles pertenecientes al conjunto habitacional "La Foresta de Rancagua", que a esa fecha estaba en construcción, pactándose en cada caso el precio que fue pagado en esa misma oportunidad al contado y a satisfacción de la promitente vendedora, previo acuerdo de que el contrato prometido se celebraría una vez que se obtuviera la recepción final del conjunto habitacional siendo, en todo caso y dependiendo de la convención, el plazo máximo fijado a más tardar con fecha 25 de enero o 31 de septiembre de 2008, respectivamente. b) Para asegurar el cumplimiento de los contratos de promesa de compraventa, en la cláusula octava de todos ellos se dejó constancia que Inmobiliaria Benanto S.A. tomó en cada caso una póliza de garantía de la compañía Mapfre Garantías y Crédito S.A., según se hizo constar mediante certificado emitido por la empresa aseguradora, que los promitentes compradores declararon recibir a su entera 


\subsubsection{Tan pronto el tomador o afianzado incurra en una acción u omisión que pueda dar lugar a una obligación que deba ser cubierta por el asegurador, el asegurado deberá tomar todas las medidas pertinentes para impedir que dicha obligación se haga más gravosa.}

satisfacción en ese mismo acto. En la referida estipulación se señaló que la póliza de garantía tomada en favor del promitente comprador garantizaba la celebración del contrato definitivo o la restitución del dinero anticipado y que podría hacerse efectiva sólo si por causas imputables a la promitente vendedora no se celebrare el contrato prometido o habiéndose celebrado no se inscribiere el inmueble en los registros pertinentes del Conservador de Bienes Raíces competente en los plazos, forma y condiciones estipuladas en los contratos de promesa de compraventa (...) f) El incumplimiento de los contratos de promesa de compraventa se verificó en la fecha máxima que en cada uno de ellos se fijó para efectos de suscribir el contrato definitivo, esto es, con fecha 25 de enero o 31 de septiembre de 2008. g) Con fecha 29 de abril de 2010, esto es, en forma previa a la presentación del reclamo ante la compañía aseguradora, las demandantes remitieron carta certificada a la afianzada Inmobiliaria Benanto S.A. requiriéndole el cumplimiento del contrato o la restitución del dinero anticipado, de conformidad a lo previsto en el artículo X de las Condiciones Generales de la póliza. h) El denuncio o reclamo del seguro a la empresa demandada se efectuó con fecha 1 de junio de 2010; TERCERO: Que tal como expresa en el artículo II de las Condiciones Generales de la Póliza de Garantía para "Contratos de Promesa de Compraventa, con Pago de Indemnización Sujeto a Liquidación", corriente a fojas 1, el objeto del seguro de marras consistía en "garantizar única y exclusivamente la obligación de restituir al asegurado las sumas de dinero que efectivamente éste hubiera pagado por anticipo o a cuenta del precio de la compraventa prometida, en todos los casos en que el tomador esté obligado a restituir tales sumas como consecuencia de no haberse otorgado el contrato prometido dentro del plazo convenido o del incumplimiento de la condición establecida por el promitente vendedor en el contrato de promesa de compraventa". A su vez, el artículo IV del citado instrumento, relativo a la vigencia de la póliza, expresa que el asegurado "podrá reclamar el pago de la indemnización sólo hasta dentro de los treinta días siguientes al término de vigencia de la póliza". Finalmente, el artículo IX del mismo documento, sobre reclamo de siniestro, establece que "Todo reclamo deberá hacerse por escrito por el Asegurado a la Compañía tan pronto haya tomado conocimiento del incumplimiento del contrato que le faculta para hacer efectiva la póliza", añadiendo, a continuación, que "El incumplimiento de esta obligación por parte del Asegurado, faculta a la Compañía para rechazar el siniestro sin que esté obligada a indemnizar suma alguna"; (...) SEXTO: Que, por su parte, en lo que atañe a dirimir la fecha máxima en que debieron las aseguradas efectuar el denuncio del siniestro, es menester reflexionar, enseguida, que una interpretación armónica y sistemática de las Condiciones Generales de la póliza de garantía, a la luz del artículo 1546 del Código Civil, de las reglas que estatuyen los artículos 1562, 1563 y 1564 del mismo estatuto legal y del deber del asegurado que prevé el artículo $524 \mathrm{~N}^{\circ} 7$ del Código de Comercio, determina necesariamente concluir que el supuesto fáctico del que pendía la exigibilidad de la póliza de garantía se verificó en este caso en la fecha en que en cada relación se hizo manifiesto que el contrato prometido no se celebró en el plazo fijado al efecto, esto es, el 25 de enero o el 31 de septiembre de 2008, respectivamente, época que (...) debe considerarse en cada caso como el de la vigencia máxima de la cobertura del seguro de garantía, por lo que, subsiguientemente, el reclamo debió ser efectuado entonces a más tardar el 25 de febrero o el 31 de octubre de 2008, según fuese el caso y, habiéndose éste verificado recién el $1^{\circ}$ de junio de 2010, es evidente que la demandada se encontraba a esa data facultada legalmente para rechazar el pago de la indemnización del siniestro que se le requirió; SÉPTIMO: Que congruentemente con lo razonado, la acción de cumplimiento de póliza de garantía debe ineludiblemente ser rechazada, toda vez que no resultan admisibles las premisas jurídicas en las que la parte demandante sustento su pretensión” (Corte de Apelaciones de Santiago, 21 de julio de 2014, Rol 5339-2013). 
6.2.3. En los mismos supuestos, tomar todas las medidas pertinentes para salvaguardar el derecho a reembolso del asegurador, en especial, interponer las acciones judiciales correspondientes.

El incumplimiento de estas obligaciones (6.2.2. y 6.2.3.) dará lugar, según su gravedad, a la reducción de la indemnización o la resolución del contrato (art. 583 del Código de Comercio). ${ }^{16}$

6.2.4. Abstenerse de actos u omisiones que puedan perjudicar el ejercicio de las acciones en que el asegurador se haya subrogado, pues en caso contrario será responsable por tales actos u omisiones (art. 534, inc. $3^{\circ}$ del Código de Comercio).

\subsection{Obligaciones del asegurador}

El artículo 582 del Código de Comercio, con la redacción de la ley 20.667 de 2013, dispone: "Por el seguro de caución el asegurador se obliga a indemnizar al asegurado los daños patrimoniales sufridos en caso de incumplimiento por el tomador del seguro o afianzado, de sus obligaciones legales o contractuales...”.

La obligación fundamental del asegurador consiste en pagar la correspondiente indemnización al asegurado en caso de siniestro. Esta es una materia que está regulada de una manera muy precisa en cada póliza y, por consiguiente, habrá que atenerse a las estipulaciones del contrato para saber cuándo se configura el siniestro y se hace exigible la obligación de indemnizar. En general, se entiende que existe siniestro cuando el tomador del seguro o afianzado no ha dado fiel y oportuno cumplimiento a la obligación que se garantiza, por causas que sean de su responsabilidad, causando con ello un perjuicio al asegurado.

En principio, y por regla general, todo siniestro da origen al procedimiento de liquidación consagrado en el artículo 61 del D.F.L. N $^{\circ} 251$ sobre compañías de seguros, liquidación que puede ser hecha directamente por la compañía aseguradora o ser encomendada a un liquidador de seguros registrado en la Superintendencia. La liquidación tiene por fin básicamente determinar la ocurrencia del siniestro, si el riesgo está bajo la cobertura de

\footnotetext{
${ }^{16}$ El artículo 583 del Código de Comercio dice: "Obligaciones del asegurado. Tan pronto el tomador o afianzado incurra en una acción u omisión que pueda dar lugar a una obligación que deba ser cubierta por el asegurador, el asegurado deberá tomar todas las medidas pertinentes para impedir que dicha obligación se haga más gravosa y para salvaguardar su derecho a reembolso, en especial, interponer las acciones judiciales correspondientes. El incumplimiento de estas obligaciones dará lugar, según su gravedad, a la reducción de la indemnización o la resolución del contrato".
} 
la póliza, y el monto de la indemnización a pagar. En este tipo de pólizas de garantía, uno de los pasos indispensables de la liquidación consiste en escuchar la opinión que sobre el reclamo de indemnización pueda formular el afianzado, toda vez que es su incumplimiento lo que se está denunciando y la admisión del reclamo y el pago de la indemnización acarrearán consecuencias en su contra, pues la compañía tiene derecho a hacer efectivo en contra del afianzado el derecho a reembolso que le reconoce el artículo 582, inc. $1^{\circ}$ in fine del Código de Comercio. La obligación de pagar la indemnización debe cumplirse de inmediato, una vez evacuado el informe de liquidación y resueltas las impugnaciones deducidas por una u otra parte, siempre que el asegurado y la compañía hayan dado su conformidad al veredicto final de la liquidación.

El inciso $2^{\circ}$ del artículo 582 referido señala que "Las excepciones $o$ defensas que el tomador oponga al asegurado, alegando que no ha existido incumplimiento de las obligaciones garantizadas por la póliza, no obstarán a que el asegurador pague la indemnización solicitada”. Dichas defensas o alegaciones deben discutirse directamente entre el tomador afianzado y el asegurado beneficiario, y no impiden que la compañía aseguradora pague el siniestro.

\section{SEGUROS DE GARANTÍA “A PRIMER REQUERIMIENTO”17}

El artículo 583 inciso final del Código de Comercio señala que el seguro de caución "podrá ser a primer requerimiento, en cuyo caso la indemnización deberá ser pagada al asegurado dentro del plazo que establece la póliza, sin que la oposición de excepciones pueda ser invocada para condicionar o diferir dicho pago". ${ }^{18}$

${ }^{17}$ Véase CAMACHO DE LOS Ríos, cit. (n. 2), pp. 115-141.

${ }^{18}$ El Oficio Circular No 972 de 13 de enero de 2017 de la Superintendencia de Valores y Seguros “precisa el alcance del inciso final del artículo 583 del Código de Comercio” en los siguientes términos: "Esta Superintendencia, en uso de sus facultades legales, en especial las señaladas en la letra a) del artículo 4 del D.L. $\mathrm{N}^{\mathrm{o}}$ 3.538; y letras e) y m) del artículo 3 del D.F.L. $\mathrm{N}^{\circ}$ 251, ha considerado pertinente precisar el marco jurídico referente a la contratación y disposiciones mínimas que deberán contener las pólizas de seguros de caución o garantía, denominados 'a primer requerimiento`, contemplados en el último párrafo del artículo 583 del Código de Comercio, a fin de atender el carácter excepcional que revisten. En éste se dispone que 'Este tipo de seguro podrá ser a primer requerimiento, en cuyo caso la indemnización deberá ser pagada al asegurado dentro del plazo que establece la póliza, sin que la oposición de excepciones pueda ser invocada para condicionar o diferir dicho pago`. 1. Pago del monto reclamado. En atención al carácter imperativo y excepcional del inciso final del artículo 583 del Código de Comercio, los seguros de garantía o caución a 'primer requerimiento`, corresponden a aquellos en que la compañía se obliga al pago del monto reclamado que no exceda del monto asegurado, dentro del plazo establecido en la póliza, a la mera solicitud del asegurado, sin que 
Para el tratadista italiano Denozza, la variedad de cláusulas que se incorporan en la práctica a los seguros de garantía dificulta la tarea de su clasificación. No obstante, en general, se podría agrupar a estos contratos de seguro en tres grandes bloques que cabría denominar como: contratos accesorios (serían los más tradicionales y próximos a la fianza); contratos a primer requerimiento ("a prima richiesta", en el lado opuesto a los contratos accesorios) y pólizas condicionadas a la entrega de determinados documentos.

Respecto de los segundos, en ellos las pólizas contienen cláusulas que estipulan "ejecución inmediata", "pronto pago", "a primer requerimiento", "a solo requerimiento" u otras formas similares, normalmente acompañadas de la renuncia por parte de la entidad aseguradora a oponer cualquier tipo de excepciones frente a la reclamación del asegurado. En estos casos, las pólizas establecen la obligación de pagar al simple requerimiento, bastando con que se haga constar la causal de incumplimiento y el monto del perjuicio sufrido. Basta al asegurado con la denuncia del siniestro en los términos que el contrato señale para que la compañía proceda al pago de la indemnización, previa verificación muy limitada de los antecedentes esenciales, fundamentalmente de si el hecho constitutivo del siniestro -la obligación incumplida- está dentro de la cobertura, de su vigencia y su monto. Haciéndose tal requerimiento (que consistirá en una declaración suscrita por el asegurado en la que consten los hechos constitutivos del incumplimiento y el monto de la indemnización solicitada), la compañía queda en obligación de pagar la

proceda exigir que el requerimiento contenga mayor información que la identificación de la póliza, del asegurado y el monto reclamado. Por lo tanto, en las pólizas de seguros de garantía o caución a primer requerimiento, no podrá exigirse o condicionarse el pago de la suma reclamada a la presentación de antecedentes adicionales a los señalados en el párrafo precedente, así como tampoco podrá diferirse el pago más allá del plazo estipulado para ello en la póliza. Lo anterior no obsta a que, en los casos que proceda por las reglas generales, se efectúe la liquidación del siniestro. 2. Declaraciones del afianzado. Las declaraciones del afianzado a que hacen referencia los artículos 524 y 525 del Código de Comercio, en caso de nulidad o resolución del contrato por la causal de errores, reticencias o inexactitudes del afianzado o tomador, por las características de los seguros de caución, no son oponibles al asegurado. 3. Recupero, subrogación y reembolso. El pago de la indemnización reclamada, en virtud de lo dispuesto en el inciso final del artículo 583 del Código de Comercio, no obsta al derecho del asegurador a ser reembolsado y al ejercicio de cualquier otra acción que éste tenga, por este motivo. 4. Denominación del modelo de póliza. De acuerdo a la primera oración, del cuarto párrafo, del número 1, del Título II, de la Norma de Carácter General N 349, los textos de pólizas deberán ser depositados con una denominación que guarde relación directa a la naturaleza del riesgo a asegurar. Por lo tanto, en los modelos de condiciones generales de pólizas de caución o garantía es posible indicar en sus denominaciones las expresiones 'a primer requerimiento', 'de pronto pago`, 'a la vista`, 'de ejecución inmediata`u otras de similar significado, sólo si se rigen por el inciso final del artículo 583 del Código de Comercio”. 
correspondiente indemnización, sin necesidad de pedir la conformidad previa del afianzado ni de hacer otra comprobación de que el requerimiento se ajusta a los términos de la póliza contratada; tampoco hay un proceso de liquidación del siniestro como es la regla general en materia de seguros.

En este tipo de póliza la obligación de pagar la indemnización debe cumplirse dentro del plazo estipulado en ella, que normalmente es de 30 días a contar del respectivo requerimiento.

Estas cláusulas “a primer requerimiento", agrega el autor citado, benefician, en la práctica, a todas las partes afectadas por el contrato: el asegurador sólo tiene que pagar ante la mera reclamación del interesado. El deudor-tomador del seguro aporta una garantía que habrá facilitado, sin duda, sus posibilidades de contratación. Y el acreedor-asegurado cuenta con una garantía personal respecto del cumplimiento de su crédito, que si bien no le garantiza el cumplimiento propiamente dicho, le otorga la seguridad de verse indemnizado en caso de incumplimiento.

En caso de reclamaciones indebidas del asegurado, un posterior juicio material resolverá el caso en su fondo, ${ }^{19}$ pero el principio fundamental de rapidez y la satisfacción inmediata de los negocios se habrá visto cubierto, en una primera fase, para todos los interesados.

Sin embargo, este tipo de cláusulas concentran, junto a sus evidentes ventajas, el mayor inconveniente de la institución: el elevado riesgo de actitudes o comportamientos dolosos del asegurado, que puede reclamar la indemnización consciente de que no le corresponde. Ese peligro, dice Denozza, desvirtúa totalmente el origen y sentido de dichas cláusulas incorporadas a los seguros con fines de garantía, y puede traducirse en una lógica desconfianza de las partes contratantes, o en la elevación necesaria de las primas para compensar dicho riesgo de reclamaciones dolosas. ${ }^{20}$

${ }^{19}$ Como dice Molina en caso de existir una discrepancia o disputa respecto del cumplimiento o no de la obligación tomador y asegurado deberán concurrir ante un árbitro o la justicia ordinaria, quien será finalmente el llamado a determinar si existió o no incumplimiento de la obligación garantizada. En el evento que mediante sentencia judicial firme y ejecutoriada se declare que el tomador no incumplió la obligación caucionada, el asegurado deberá restituir a la compañía de seguros la indemnización que haya percibido, ya que en dicho caso la indemnización constituyó una fuente de enriquecimiento o ganancia vulnerando el artículo 550 del Código de Comercio. Con todo, es pertinente precisar que aun en este caso el asegurador ha procedido como es debido, en el sentido que, cumplidos los requisitos y condiciones del contrato de seguro, ha procedido al pago de la indemnización a la cual se comprometió, sin que le corresponda o le resulte exigible ni menos imputable el hecho de haber pagado la caución por el incumplimiento de una obligación, que finalmente no existió. MolinA, cit. (n. 8), p. 727.

${ }^{20}$ F. Denozza, citado por BARREs BenLloch, cit. (n. 2), p. 108. 


\section{VIGENCIA DEL SEGURO DE GARANTÍA}

Una de las estipulaciones esenciales de toda póliza de seguros es aquella que especifica su vigencia, toda vez que sólo los eventos ocurridos durante ella estarán cubiertos.

Normalmente las pólizas de seguros de daños, como lo son los seguros de garantía, se extienden para durar un lapso de tiempo cronológico absolutamente preciso, como lo es seis meses, un año, dieciocho meses, etc. Sin embargo, nada obsta a que la póliza de seguro se extienda para durar lo mismo que el término de un contrato o de las obligaciones que de él surjan, lo que es perfectamente factible y normal en una póliza de seguro de garantía que, como toda caución, está en principio ligada a la obligación caucionada.

Las cláusulas de las pólizas de seguro de garantía no modifican mayormente los principios expuestos, pero generalmente agregan que la caducidad del plazo de vigencia de la póliza no extingue la responsabilidad de la compañía para con el asegurado por incumplimiento de obligaciones garantizadas que se hayan producido durante su vigencia. Pero en estos casos, en beneficio de la certeza jurídica, se establece un plazo máximo para que, luego de expirada la vigencia del seguro, pueda el asegurado reclamar el pago de un siniestro, plazo que en algunos modelos de pólizas es de treinta días contados a partir del fin de la vigencia del seguro.

Igualmente, la generalidad de las pólizas señala que la devolución de las mismas por el asegurado a la compañía, antes del término de la vigencia de la cobertura, implica por parte del asegurado renuncia de sus derechos a reclamar indemnización con cargo a dichas pólizas.

\section{CONCLUSIONES}

Tanto el seguro de garantía como el seguro de crédito tienen por objeto cubrir el riesgo de una obligación incumplida, pero en el primero lo que se garantiza son obligaciones de hacer o no hacer mientras que el seguro de crédito protege el incumplimiento de obligaciones de dinero.

Las más variadas razones, como se detalló, justifican no calificar el seguro de garantía como una fianza, de ahí que se critique que la Ley $\mathrm{N}^{\circ}$ 20.667 hable del "afianzado".

Este tipo de seguros puede ser calificado como uno por cuenta ajena, pues se da la particularidad que el tomador no es el beneficiario, como ocurre 
en la mayoría de los seguros, sino que lo es la contraparte que exige una garantía ante un eventual incumplimiento del tomador.

A pesar de que los nuevos artículos 582 y 583 del Código de Comercio no lo dicen, la doctrina está conteste que por la misma naturaleza y objeto del seguro de garantía el asegurador no puede alegar la falta de pago de la prima para no pagar el siniestro, en este caso el incumplimiento por parte del tomador de sus obligaciones. Aceptar lo contrario significaría que estos seguros perderían toda utilidad.

En este tipo de seguros las excepciones o defensas que el tomador oponga al asegurado, alegando que no ha existido incumplimiento de las obligaciones garantizadas por la póliza, no obstan a que el asegurador pague la indemnización solicitada.

Pesa sobre el asegurado -obligaciones ahora consagradas legalmentetan pronto el tomador o afianzado incurra en una acción u omisión que pueda dar lugar a una obligación que deba ser cubierta por el asegurador, tomar todas las medidas pertinentes para impedir que dicha obligación se haga más gravosa y para salvaguardar el derecho a reembolso del asegurador, en especial, interponer las acciones judiciales correspondientes.

La Ley $\mathrm{N}^{\circ} 20.667$ consagró legalmente los seguros de garantía “a primer requerimiento" que ya eran usados ampliamente en el tráfico mercantil. Con ellos se busca agilizar y hacer lo más expedito posible el pago por parte del asegurador; de ahí que el artículo 583 citado disponga que en estos seguros la indemnización deberá ser pagada al asegurado dentro del plazo que establece la póliza, sin que la oposición de excepciones pueda ser invocada para condicionar o diferir dicho pago.

\section{BIBLIOGRAFÍA}

Achurra Larraín, Juan, “Aspectos Jurídicos del Seguro de Garantía”, en AA.VV., Re-Capacitando, American Re-Insurance Company (Chile) S.A., Santiago, 1992, Vol. II.

ACHURRA LARRAín, Juan, Derecho de Seguros, Editorial Universidad de los Andes, Santiago, 2005.

BACHILler NúÑEz, Julio; BACHILler, Sergio; PÉREZ EtChegoyen, Julia, Seguro de Caución, Abeledo Perrot, Buenos Aires, 1995.

Barres Benlloch, María Pilar, Régimen Jurídico del Seguro de Caución, Aranzadi, Pamplona, 1996. 
Broseta Pont, Manuel, Manual de Derecho Mercantil, Tecnos, Madrid, 1991.

CAMACHO DE LOS Ríos, Javier, El Seguro de Caución. Estudio Crítico, Mapfre, Madrid, 1994.

CONTRERAs STRAUCH, Osvaldo, Jurisprudencia sobre Seguros. Recopilación y Análisis, Editorial Jurídica de Chile, Santiago, 1999.

Contreras Strauch, Osvaldo; Prado Puga, Arturo, El Contrato de construcción y sus Principales Garantías, publicación del Colegio de Abogados de Chile, Santiago, 1996.

FARAGGi, SALAZAR, CONTRERAS y GOÑ ABOgAdos (EDITOR), “El Seguro de Garantía”, en AA.VV., Re-Capacitando, Compañía Reaseguradora Bernardo O’Higgins S.A., Santiago, 1985, Vol. I.

Hoyos ElizALDE, Carlos, El Seguro de Caución: una aproximación práctica, Mapfre, Madrid, 2007.

Molina ZALdívar, Carlos, “Artículo 583”, en AA.VV., El Contrato de Seguro. Comentarios al Título VIII, Libro II del Código de Comercio, Thomson Reuters, Santiago, 2015. 